\title{
Study on Microstructure of Aluminum / Steel Self - riveting - Resistance Spot Welding Joint
}

\author{
Yugang $\mathrm{He}^{1,}$,, Ranfeng Qiu ${ }^{1,2}$, NingWang $^{1}, \mathrm{DanLi}^{1}$ \\ ${ }^{1}$ School of Materials Science and Engineering, Henan University of Science and Technology, \\ Luoyang, 471003, China; \\ ${ }^{2}$ Collaborative Innovation Center of Nonferrous Metals, Henan Province, Luoyang, China; \\ a13137055607@163.com, *quiur1221@163.com
}

\begin{abstract}
Keywords: self-riveting, resistance spot welding, aluminum alloy, low carbon steel
Abstract. In this paper, A6061 aluminum alloy and Q235 steel were used as the research object, and the bonding interface of the joint was observed by electron beam microscope. The tensile test was carried out by using a tensile tester. The results show that the riveting joints of aluminum /steel are not produced by the intermediate compounds. But the riveting and resistance spot welding joints of aluminum /steel are produced by the intermediate compounds. The airtightness and stability of the joints are improved. The strength of the joints of the riveting and spot welding is higher than that of the riveted joints.
\end{abstract}

\section{Introduction}

With the rapid development of modern technology, the emergence of new materials and the connection of dissimilar materials, and with other disciplines cross each other, promote each other, has become the forefront of science and technology and pillars. With the rapid development of modern industry and the continuous progress of science and technology, the overall performance requirements of the components are also increasing, but in general a single metal structure is usually difficult to meet the needs of industrial production. Aluminum and aluminum alloy density is low, with excellent corrosion resistance and good weldability and other characteristics, in the national defense construction and national economy widely used, second only to the most widely used steel, at present, the global environment The situation is grim and the energy is tightening. All countries in the world have implemented policies to conserve energy to protect the environment. The use of less lightweight metals, such as $\mathrm{Al}$ and $\mathrm{Mg}$, to reduce the weight of parts has become the aerospace industry, vehicle manufacturing and other areas of the focus of the study ${ }^{[1]}$. The connection between the two metals of steel and aluminum can combine the advantages of the two and reduce the weight and improve the economic efficiency. Vehicles made of aluminum / steel made of components can reduce their own weight, improve energy efficiency and reduce pollution ${ }^{[2]}$. But there is a large physical and chemical properties between the aluminum / steel, welding is easier to produce cracks and not fusion and so on, so dissimilar metal aluminum / steel through welding to obtain high-quality joints become a major problem in the field of manufacturing processing .

Many scholars at home and abroad are increasingly concerned about the importance of aluminum / steel heterogeneous material connections. Friction welding ${ }^{[3]}$, friction stir welding ${ }^{[4]}$, resistance spot welding ${ }^{[5]}$ and other welding methods were used for aluminum / steel dissimilar material connections, but before The results show that there are some problems with welded joints obtained by using a single welding method. For example, friction welding can obtain better welded joints, but the size and shape of the parts are too high and it is difficult to realize automation and mass production. Spot welding of aluminum / steel welding, joint interface will produce a brittle hard intermediate reaction layer, affecting the strength of the joint. In this paper, the aluminum alloy / steel was welded by the self punching - resistance spot welding method, and the microstructure and mechanical properties of the welded joint were analyzed. On this basis, the reliability of the composite welding process was discussed.Organization of the Text. 


\section{Test materials and methods}

The $1.5 \mathrm{~mm}$ thick aluminum alloy and $2 \mathrm{~mm}$ carbon steel sheet were treated into sheets of $100 \mathrm{X}$ $30 \mathrm{~mm}$ and $100 \times 30 \mathrm{~mm}$, and the chemical composition was shown in Table 1. Test joints using lap form shown in Fig.1, In the process of self piercing riveting and resistance spot welding, the aluminum alloy plate is always on the top.

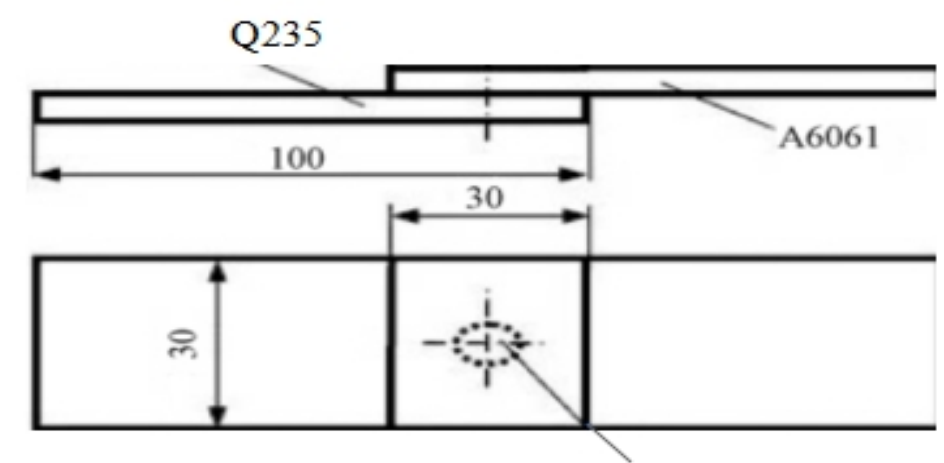

Riveting area

Fig. 1 Riveting sample lap diagram

Table 1 Chemical composition of A6061 aluminum alloy and Q235 steel

\begin{tabular}{ccccccc}
\hline Material & $\mathrm{Cr}$ & $\mathrm{Cu}$ & $\mathrm{Ti}$ & $\mathrm{Mg}$ & $\mathrm{V}$ & $\mathrm{C}$ \\
\hline A6061 & 0.04 & 0.3 & 0.15 & 1.0 & - & - \\
Q235 & - & - & - & - & 0.06 & 0.14 \\
\hline Material & $\mathrm{P}$ & $\mathrm{S}$ & $\mathrm{Si}$ & $\mathrm{Mn}$ & $\mathrm{Fe}$ & $\mathrm{Al}$ \\
\hline A6061 & - & - & 0.6 & 0.15 & - & Bal. \\
Q235 & 0.04 & 0.2 & 0.4 & 1.0 & Bal. & - \\
\hline
\end{tabular}

The aluminum alloy and steel were riveted by self-piercing and riveting, and the riveting point of the riveting joint was welded with a fixed-point welding machine. Five samples were welded under each parameter, two were used for making metallographic test samples, The other three were used for tensile tests to analyze the tensile strength of the joint. Before riveting, the surface of rivets, aluminum alloy and steel plate thoroughly cleaned and dried. The process parameters are shown in Table 2 . After welding, cut along the diameter of the solder joint, grinding and polishing. The microstructure of interface interface was observed by scanning electron microscopy. The tensile test was carried out using a tensile tester.

Table 2 composite welding process parameters

\begin{tabular}{ccccccc}
\hline $\begin{array}{c}\text { Riveting } \\
\text { load }\end{array}$ & $\begin{array}{c}\text { Rivet } \\
\text { height }\end{array}$ & $\begin{array}{c}\text { Welding } \\
\text { current }\end{array}$ & $\begin{array}{c}\text { Electrode } \\
\text { pressure }\end{array}$ & $\begin{array}{c}\text { Welding } \\
\text { time }\end{array}$ & $\begin{array}{c}\text { Upper } \\
\text { electrode }\end{array}$ & $\begin{array}{c}\text { Lower } \\
\text { electrode }\end{array}$ \\
\hline $23-25(\mathrm{KN})$ & $6(\mathrm{KN})$ & $6-10(\mathrm{KA})$ & $3(\mathrm{KN})$ & $0.4(\mathrm{~S})$ & $\varphi 8(\mathrm{~mm})$ & $\varphi 10(\mathrm{~mm})$ \\
\hline
\end{tabular}

\section{Test results and analysis}

In a certain range, each time interval $0.5 \mathrm{KN}$, change the riveting load riveting, when the riveting load is less than $23 \mathrm{KN}$, the rivets can not be completely inserted into the steel plate, failed to achieve effective connection. And when the riveting load is higher than $25 \mathrm{KN}$, the lower side of the specimen is pierced, resulting in cracks, affecting the appearance of the joint appearance, is not conducive to 
follow-up spot welding. The riveted specimen was subjected to a tensile test, the riveting load and the tensile strength of the joint, as shown in Fig2. It can be seen that the tensile strength of the joint increases with the increase of the riveting load and reaches the maximum value of $3.86 \mathrm{KN}$ when the riveting load is $25 \mathrm{KN}$. However, when the riveting load exceeds $25 \mathrm{KN}$, the tensile strength of the joint decreases as the riveting load increases.

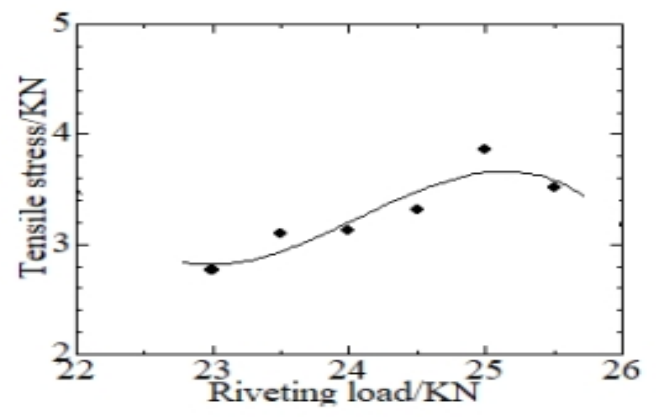

Fig .2 Curve of riveting load and tensile strength of joint

The riveting load of $24.5 \mathrm{KN}$ after the riveting of the sample, in a certain range to change the welding current for welding, when the welding current is less than 5KA, the resistance heat is less than the melting point of the material, the material can not melt difficult to achieve welding. When the welding current is greater than 10KA, the welding process produces severe splash, surface metal burns serious. The tensile test was carried out in the welded test, and the relationship between the welding current and the tensile strength of the joint was shown in Fig. It can be seen that the tensile strength of the joint increases first and then decreases with the increase of the welding current, and reaches the maximum value of $3.57 \mathrm{KN}$ when the welding current is $8 \mathrm{KA}$. when the riveting load is $24.5 \mathrm{KN}$, the tensile strength of the caulked specimen is $3.13 \mathrm{KN}$. As can be seen from Figure 3, since the riveting resistance spot welding of the welding joint tensile strength is greater than $3.13 \mathrm{KN}$. So the self-punching riveting - resistance spot welding of the joint welding joint tensile strength is greater than the tensile strength of a single self-punching riveting joints.

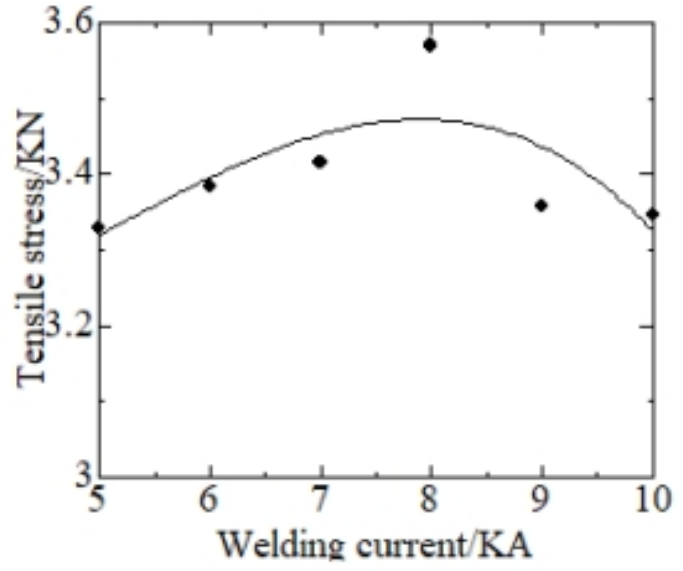

Fig. .3 Curve of welding current and joint tensile strength in composite welding

Since the self-riveting is essentially a mechanical connection technique, the material to be joined is not a combination of metallurgical bonds, and the interface is free from intermediate compounds. The tightness and stability of the riveted joints are poor. The welding joint obtained by the composite welding method of the riveting-resistance spot welding is shown in Fig. 4 (a), and the cross section of the aluminum / steel composite welding head. It can be seen from the figure, the rivet and the plate is very close, and a good mechanical self-locking performance, but the rivet under the aluminum in the emergence of a larger "stomata", It is the shrinkage hole formed in the cooling process after welding. The reason may be that the welding current is too large and spatter occurs during welding, which leads 
to the loss of molten metal liquid and can not be filled by cooling and solidification.
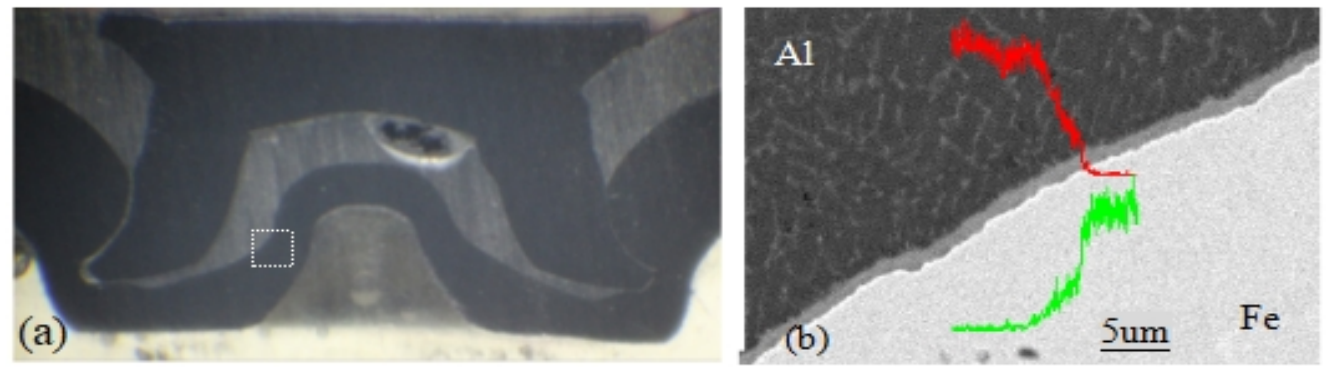

Fig .4 . (a) aluminum / steel composite welding cross section,

(b) composite welding joint interface SEM image

Fig. 4 (b) is an enlarged image of the white dotted frame region in (a). As can be seen from the figure, the aluminum / steel interface has a reaction layer and a thickness of about $2 \mathrm{um}$, and the aluminum / steel interface reaction layer contains $\mathrm{Al}$ and $\mathrm{Fe}$, and the reaction layer is an intermetallic compound of aluminum and iron. Therefore, an intermediate reaction layer is formed on the interface of the composite welded joint to improve the tightness and stability of the joint.

\section{In conclusion}

The reaction layer was not observed in the interface area of the aluminum alloy and the low carbon steel self-piercing joint. Aluminum alloy and low carbon steel to take self-riveting - resistance spot welding, the joint interface with a reaction layer generated area. Aluminum alloy and low carbon steel riveting - spot welding joints and riveting joints compared to the connector air tightness and stability has greatly improved. aluminum alloy and low carbon steel riveting - spot welding, with the welding current increases, the joint strength first increased and then reduced, and since the riveting - resistance spot welding joints and self-riveting riveting compared to self-riveting resistance Spot welding of the joint strength is higher.

\section{Acknowledgements}

This work was supported by the Natural Science Foundation of China (U1204520), Henan Province Support Plan of Universities and Colleges Innovation Talents (16HASTIT050), Henan Province International Science and Technology Cooperation Projects ( 162102410023 ).

\section{References}

[1] PB Berbon ,WH Bingel,et al.Friction stir processing: a tool to homogenize nanocomposite aluminum alloys.Scripta Materialia , 2001 , 44 (1) :61-66

[2] Haraga K. Strength properties of aluminum/aluminium and aluminium/steel joints for light weighting of automotive body [J].Welding in the World , 2004.

[3] Yilmaz M,Col M.Acet M.Interface properties of aluminum/steel friction welded components [J].Materials Characterization , 2003 , 49: 421 - 429 .

[4] Lee W B , Schmuecker M,Mercardo U A,et al.Interface reaction in steel alu -minum joints made by friction stir welding[J].Scripta Materialia,2006,55: $355-358$. 
[5] Qiu Ranfeng ,Iwamoto Chihiro ,Satonaka Shinobu .The influence of reaction layer on the strength of aluminum/steel joint welded by resistancespot welding[J]Materials Characterization , 2009 , 60: $156-159$. 